\title{
Position-sensitive detector based on plastic scintillator for muon tomography
}

\author{
A.I.Ivanov, V.A.Tarasov, V.Y.Pedash \\ Institute for Scintillation Materials, STC "Institute for Single Crystals" \\ National Academy of Sciences of Ukraine, 60 Lenin Ave., 61001 Kharkiv, \\ Ukraine
}

Received July 07, 2014

\begin{abstract}
The analysis of the different models of a plastic position-sensitive detector construction for muon tomography is discussed. The key feature of the detectors is the ability of, a passive registration of ionizing radiation from the inspected object. The optimal configuration of the detector has been determined, and its main parameters in both modes of operation has been assesed.
\end{abstract}

Keywords: plastic position-sensitive detector, muon tomography.

Приведен анализ различных моделей построения пластикового позиционно-чувствительного детектора для мюонной томографии, обладающего также возможностью пассивной регистрации ионизирующего излучения, исходящего от объекта исследования. Выявлены оптимальные конфигурации такого детектора, а также оценены его основные параметры в обоих режимах работы.

Позиційно-чутливий детектор на основі пластикових сцинтиляторів для мюонної томографії. О.І.Іванов, В.О.Тарасов, В.Ю.Педаш.

Приведено аналіз різних моделей побудови пластикового позиційно-чутливого детектора для мюонної томографії, здатного до пасивної реєстрації іонізуючого випромінювання, що надходить від об'єкта дослідження. Виявлено оптимальні конфігурації такого детектора, а також оцінено його основні параметри в обох режимах роботи.

\section{Introduction}

Muon tomography is a promising method for the inspection of various shipping containers for the presence of smuggled objects. The advantages of devices for muon tomography i.e. muon tomographs (MTs) include the absence of additional radiation load on the object to be inspected. Such a device does not require additional means for personnel protection against ionizing radiation. The main disadvantage of all the systems, which use naturally occurring muons (p.e. muons arising in of extensive air showers), including MTs, is a sufficiently long scanning time. This characteristic, however, becomes not to be decisive for large-size inspected objects. For example, the scanning speed of high-capacity container introscopes is $1-2 \mathrm{~m} / \mathrm{min}$, which corresponds to the screening time of 3-6 $\mathrm{min}$ for a 20 -foot container. Available prototypes of muon tomographs can conduct a similar scan in 15 min [1-3]. So, MT can become quite competitive in the market of inspection systems provided that its cost is reduced to a level comparable with $\mathrm{X}$-ray scanners.

Currently, attempts are being made to develop a MT that based on plastic scintillation detectors $[4,5]$. Unlike the similar systems using drift tubes, they do not require periodic replacement of the gas mixture, and can have a reduced number of positionsensitive (PS) layers, because a drift tube has positional sensitivity along one coordi- 
nate, but the scintillation plastic enables the design of a two-coordinate PS detector.

It should also be noted that the muons have a sufficiently high penetrating power that puts the muon tomography in a row with a neutron radiography which is extremely effective for cargo screening with a large amount of dense material, but requires enhanced protection and activate inspected cargo.

The possibility to use a plastic positionsensitive detector for muon tomography is investigated in the paper. We also discuss operation of such a detector in passive mode (as radiation portal monitor). The MTs are not able to directly detect nuclear materials in the inspected object. Large area plastic scintillators allow this mode of operation. The paper discusses three types of plastic detectors and compares their performance in both detection modes.

\section{Subject and methods}

Muon tomography is based on the measurement of deflection angle and momentum of the muon in a substance $[1,2]$. If these two values are known, the following formula allows to estimate the atomic number of the material through which the muon passed [1, 2]:

$$
\langle\theta\rangle \approx \sqrt{\frac{\pi}{2}} \frac{13.6 M e V}{v p} \sqrt{L / L_{0}}\left[1+0.038 \ln \left(L / L_{0}\right)\right],
$$

where $\langle\theta\rangle$ - the deflection angle of the muon, $v \approx c$ - the speed of the muon, $p$ - its momentum, $L$ - length of the muon track and $L_{0}$ - radiation length for a given material, which depends on the atomic number. The angle is measured using two PS detectors mounted above the examined object and two similar detectors installed just below it. At least one more detector and a material layer of a known thickness and density are required to measure the muon momentum. It can be calculated from the results of a deflection of the muon in a known substance.

So MT can be built on the basis of identical PS detectors. Each of these detectors must have:

- The best possible spatial resolution for muons in the energy range $1-10 \mathrm{GeV}$. Most of muons originating from extensive air showers have such energies.

- Spatial resolution must be kept in the largest possible range of zenith angles. The distribution of muons along the zenith angles $\theta$ is proportional to $\cos ^{2} \theta$.

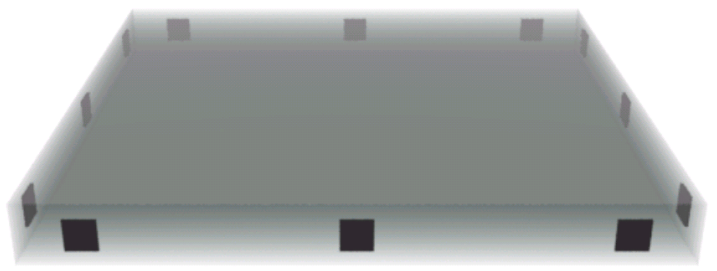

Fig. 1. Detector with light collection from the side faces.

- The least possible number of photodetectors, because it directly influences the final cost of the MT.

- Sensitivity to gamma rays of energies above $100 \mathrm{keV}$. It will ensure the possibility of passive detection of most radioactive isotopes (radiation portal mode) by MT.

Since some of mentioned requirements contradict each other, it is necessary to optimize the design of the detector. We chose the Monte Carlo simulation package GEANT4 to model main parameters of the detectors. It is proved to be accurate and efficient in modeling the interactions of low- and high-energy particles. It also allows paralleling of the modeling process. The latter is extremely important because the processes such as multiple Coulomb interactions of muons with matter and propagation of visible light photons in wavelength shifting fiber require significant computational resources.

The first option considered in the paper is PS detector based on plastic scintillator with the collection of light from the side faces (Fig. 1). We used square $1 \times 1 \mathrm{~cm}^{2}$ surfaces as windows registering visible light photons and simulating photodetectors. The quantum efficiency of each photodetector was assumed to be 0.5 . The scintillator thicknesses of $1-2 \mathrm{~cm}$, dimensions of $20 \times 20-30 \times 30 \mathrm{~cm}^{2}$ were simulated. The number of windows ranged from 3 to 5 for each side face.

The second option considered is PS detector based on plastic scintillator with the collection of light from the bottom face (Fig. 2). In this case we also modeled scintillators of $1-2 \mathrm{~cm}$ thickness, and varied number of windows per unit length of the detector (from 3 to 5 to $20 \mathrm{~cm}$ in length).

A third variant of the detector represents a strip plastic scintillator with cross section of $1 \times 1 \mathrm{~cm}^{2}$. The light collection is carried out by WLS fibers (Fig. 3). Readout photodetectors are placed at both ends of the fiber. Since the collection of light by 


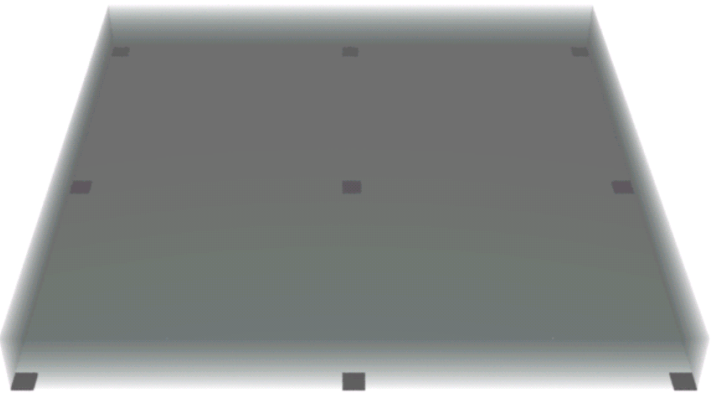

Fig. 2. Detector with light collection from the bottom face.

the fiber brings to the photodetectors only $20 \%$ of the scintillation photons, the detector becomes insensitive to gamma rays of low energy. Therefore, auxiliary photodetectors located directly on the plastic scintillator were added to the design. They are intended exclusively for radiation portal monitor (RPM) mode. Detectors with the length $0.5 \mathrm{~m}$ and $1 \mathrm{~m}$ have been modeled, and the number of photodetectors for RPM mode has been changed from 2 to 6 per meter.

The third variant is similar to the twocoordinate detector, considered in [5]. It is based on continuous scintillator with WLS fibers on both sides. The direction of the fibers situated on different sides is perpendicular. RPM mode in this detector can be implemented by the installation of additional photodetectors at the side faces.

Spatial resolution is determined as follows: at the first stage each detector is calibrated by minimizing the mean-square deviation of the detector response from the real position of the incident muon. Muons are emitted strictly perpendicular to the detector in a grid with a step of $3-5 \mathrm{~mm}$. At the second stage the muons are emitted in a grid with larger steps. The distribution of the incident zenith angles is assumed to be equal $\cos ^{2} \theta$ and cut at 30 degrees. Each of the peaks in detector response is approximated by a Gaussian distribution and a spatial resolution is taken as the full width at half-maximum of the Gaussian curve.

For each of the three variants we also evaluated the feasibility of fast neutron detection. New plastic scintillators with pulse shape discrimination ability of neutrons and gamma signals [6] make possible combining neutron and gamma detectors for RPM mode. The lower cutoff energy for the neutrons, as well as detection efficiency, however, should inevitably be lower than those

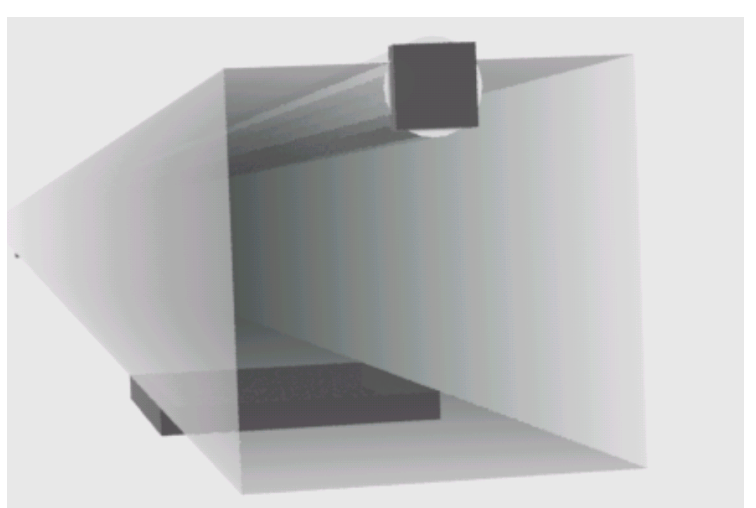

Fig. 3. Detector with WLS fiber.

presented in [6], because of the deterioration of light collection.

The simulation used a list of physical processes (so-called "physics list") based on the built-in GEANT4 list QGSP_BERT_HP. It includes high-precision neutron model and standard package of electroweak interactions. Additional physics processes have been attached to support simulation of scintillations, optical absorption and Rayleigh scattering of visible light photons, as well as their reflection and refraction at the boundaries. Simulation of scintillations is performed as follows: at each step of the primary particle track the lost of energy is calculated. In accordance with this value and the light yield of the scintillator (in this paper it is assumed to be 12,000 photons/MeV for plastic) the number of generated visible light photons is calculated. Photons are uniformly distributed over the step; emission assumed to be isotropic; emission spectrum and decay time spectrum are defined empirically at the initialization stage.

\section{Results}

Position sensitivity of the detector with light collection from the side faces (Fig. 1) is largely dependent on the light-reflecting properties of the scintillator packaging. The best results were obtained for blackened scintillator faces. In this case the detector showed the following spatial resolution in the center (the muon energy was $4 \mathrm{GeV}$ ): $0.8 \mathrm{~cm}$ for a detector of $1 \mathrm{~cm}$ thickness and $1.3 \mathrm{~cm}$ for a detector of $2 \mathrm{~cm}$ thickness. The detector has zones without positional sensitivity - the corners between the outer photodetectors. The blackening of the faces, however, significantly deteriorates the detector sensitivity to gamma rays of low energy. To eliminate this drawback a diffuse reflector should be placed on the faces of the scintillator, though in this case the spa- 


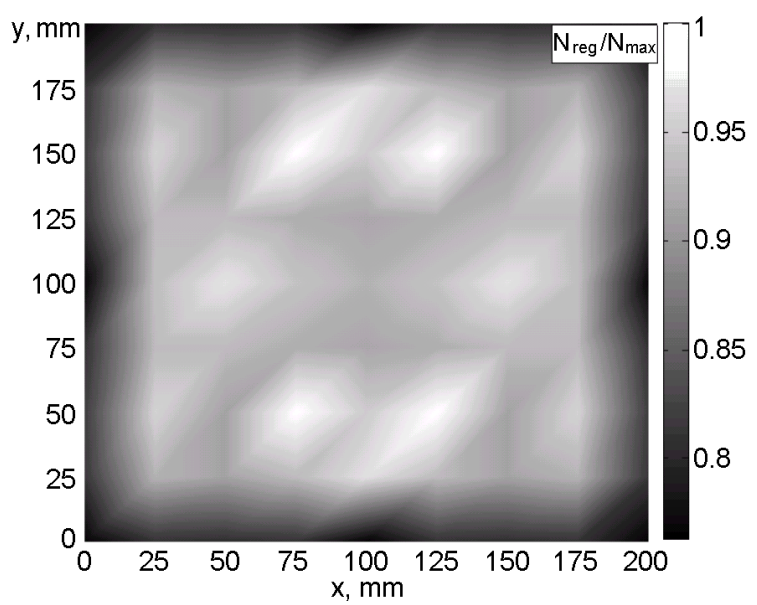

Fig. 4. The dependence of the light output on the coordinates for the detector with the collection of light from the side faces.

tial resolution decreases. Figure 4 shows the profile of light-collection for the detector thickness of $1 \mathrm{~cm}$, dimensions $20 \times 20 \mathrm{~cm}^{2}$ and the energy of the incident gamma rays of $100 \mathrm{keV}$. One can see the detector has a sufficiently small non-uniformity of light collection. Figure 5 shows the dependence of the detection efficiency on the energy of gamma rays for three thicknesses of detectors. The increase in the thickness results in increase of detection efficiency, but, at the same time, it leads to reduced spatial resolution.

The detector collecting the light from the lower face (Fig. 2) showed the following spatial resolution in the center (the muon energy was $4 \mathrm{GeV}$ ): $0.7 \mathrm{~cm}$ for a detector of $1 \mathrm{~cm}$ thickness and $1.2 \mathrm{~cm}$ for a detector of $2 \mathrm{~cm}$ thickness. Spatial resolution slightly reduces near the sides. The detector has more pronounced non-uniformity of lightcollection (Fig. 6) and therefore will provide greater detection threshold at low energies. Both of these results were obtained for the case of a diffuse reflector on the faces of the detector. By the combination of characteristics the detector showed the better performance than the one with the collection of light from the side faces.

Detector with WLS fiber (Fig. 3) with $1 \mathrm{~m}$ width at normal incidence of muons with energy $4 \mathrm{GeV}$ showed a spatial resolution of about $1 \mathrm{~mm}$. The light collection at bottom-face photodetectors is about $0.25-$ 0.3 from the total number of photons of the scintillation (the number of photodetectors is equal to 5). This quantity is sufficient for the detection of gamma rays with energies of $100 \mathrm{keV}$ and above.

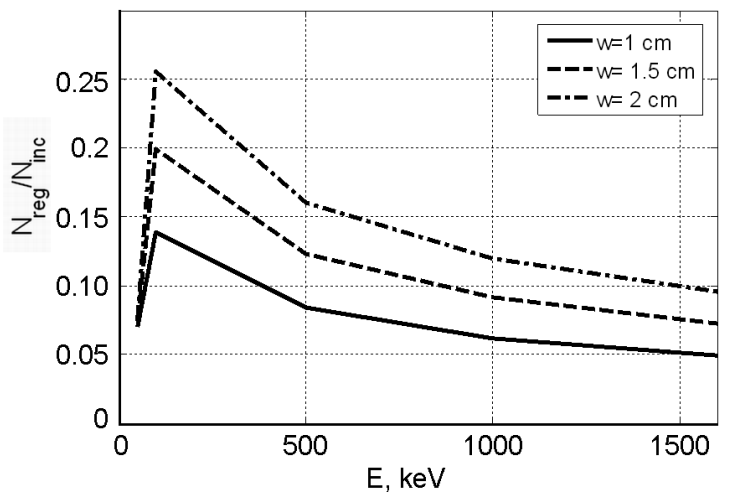

Fig. 5. The dependence of the detection efficiency on the energy of gamma rays for the detector with the light collection from the side faces. The solid, dotted and dashed line corresponds to the thickness of $1 \mathrm{~cm}, 1.5 \mathrm{~cm}$ and $2 \mathrm{~cm}$, respectively.

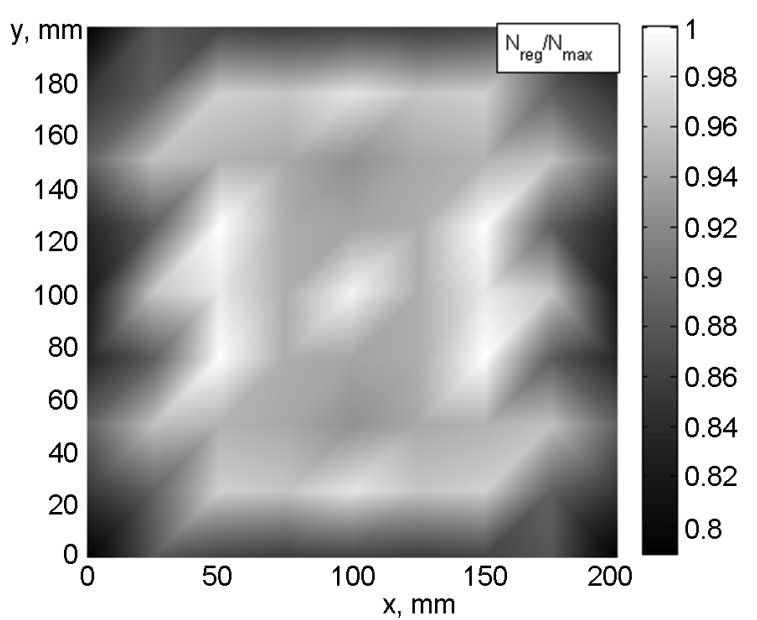

Fig. 6. The dependence of the light output on the coordinates for the detector with the collection of light from the bottom.

Concerning the neutron detection, all three detectors have approximately the same sensitivity, which decreases from about $1.5 \%$ for the neutrons with energy of $300 \mathrm{keV}$ to $0.07 \%$ for neutrons with energy of $2 \mathrm{MeV}$ (These results are valid when the thickness of the detector equals to $1 \mathrm{~cm}$ ).

\section{Conclusions}

According to the results of modeling, the detector with WLS fiber shows the best performance among the three considered designs. It provides sufficient positional sensitivity for MT, as well as sensitivity to gamma rays with energy of $100 \mathrm{keV}$ and above. This detector can also be used for fast neutron detection provided that it is based on a plastic with gamma/neutron dis- 
crimination. Since the inspection of the container by MT takes a few minutes, and the area of the detectors is much larger than the area of detectors in RPMs, it is expected that the sensitivity of the system in passive mode will be several times greater than the one of conventional radiation portal monitors.

\section{References}

1. C.L.Morris, C.C.Alexander, J.D.Bacon et al., Scie. \& Global Security, 16, 37 (2008).
2. A.A.Borisov, M.Y.Boholubsky, N.T.Bozhko et al., Preprint IFVE 2011-7, Protvino (2011).

3. L.J.Schultz, G.S.Blanpeid, N.Borozdin et al., IEEE Trans.Image Processing, 16, 1985 (2007).

4. S.Riggi, V.Antonuccio-Delogu, M.Bandieramonte et al., Nucl. Instrum. Meth. Phys. Res. $A, 728,59$ (2013).

5. Woo Jin Jo, Hyun-Il Kim, Su Jung An et al. Nucl. Instrum. Meth. Phys. Res. A, 732, 568 (2013).

6. P.N.Zhmurin, V.N.Lebedev, V.D.Titskaya et al., Functional Materials, 21, 282 (2014). 